\title{
Percepção de agentes comunitários de saúde sobre os usuários de álcool e outras drogas
}

Perceptions of community health agents about users of alcohol and other drugs

Larissa Sandy Carvalho Teles ${ }^{1}$, Emilene Hessel Correa ${ }^{1}$,

Fátima Ayres de Araújo Scattolin ${ }^{1}$

\begin{abstract}
RESUMO
Introdução: A dependência química tem sido centro de debates em vários setores, tanto governamentais como na sociedade em geral. Apresenta-se como um grave problema social e de saúde pública. Objetivos: Conhecer o perfil dos agentes comunitários de saúde (ACS) das Unidades Saúde da Família do município de Sorocaba, São Paulo, e identificar a percepção e as formas de intervenção desses profissionais em relação ao uso e abuso de drogas no território. Material e Métodos: Trata-se de estudo exploratório, descritivo, transversal, predominantemente qualitativo. Foram utilizados como instrumentos de coleta de dados: questionário sociodemográfico e entrevista com roteiro semiestruturado. Resultados e Discussão: Os dados foram analisados pela técnica do discurso do sujeito coletivo. Participaram 64 ACS, sendo $98,4 \%$ mulheres, $90,6 \%$ casadas, $92,1 \%$ de religião cristã, média de 11,2 anos de estudo, 4,9 anos de profissão e média de idade de 36,8 anos. Foram consideradas cinco categorias: drogas como um dos maiores problemas do bairro, identificação do usuário, intervenções, capacitação para as intervenções, e redução de danos. Conclusões: Os ACS consideram que as drogas representam um dos maiores problemas que atingem a sociedade. Reclamam da falta de capacitação para intervenções efetivas com os usuários. Suas relações sociais e profissionais os levam a associar o problema à violência e ao medo, mas entendem que as ações devem ser desenvolvidas com a permissão e participação do usuário e que a postura do profissional deve ser compreensiva e inclusiva. Na percepção dos ACS é preciso buscar formas de reduzir os danos e melhorar a saúde e qualidade de vida dos usuários.
\end{abstract}

Palavras-chave: agentes comunitários de saúde; transtornos relacionados ao uso de substâncias; saúde mental; atenção primária à saúde.

\begin{abstract}
Introduction: Chemical dependency has been the center of debates in governmental and non-governmental sectors and presents itself as a serious social and public health problem. Objectives: To investigate the profile of community health agents (CHA) from the city of Sorocaba, São Paulo, Brazil, and to identify their perceptions regarding the use and abuse of drugs in the territory, as well as the interventions used by these professionals. Material and Methods: This is an exploratory, descriptive, transversal, predominantly qualitative study. The instruments chosen to collect data were a sociodemographic questionnaire and a semi-structured interview. Results and Discussion: Data were analyzed by the technique of the collective subject discourse. A total of 64 CHA were included, being $98.4 \%$ women, $90.6 \%$ married, 92.1\% Christians, with an average of 11.2 years of study, 4.9 years of labor and an average age of 36,8 years. Data analyzed were grouped into five categories: drugs are one of the biggest problems in the neighborhood, user's identifications, interventions, training for interventions, and harm reduction. Conclusions: The CHA consider drugs as one of the biggest problems affecting society. However, they feel a lack of training for effective interventions with users. Their social and professional relationships lead to represent the problem as a phenomenon linked to violence and fear, but they also understand that actions must be carried out with the permission and participation of the users and that professionals should be primarily supportive and inclusive. From the CHA perception, it is necessary to seek ways to reduce the harm and to improve health and quality of life of users.
\end{abstract}

Keywords: community health workers; substance-related disorders; mental health; primary health care.

${ }^{1}$ Pontifícia Universidade Católica de São Paulo (PUC-SP), Faculdade de Ciências Médicas e da Saúde - Sorocaba (SP), Brasil. Contato: larii.sandy@ hotmail.com

Recebido em 05/09/2015. Aceito para publicação em 29/02/2016. 


\section{INTRODUÇÃO}

$\mathrm{O}$ tema uso e abuso de drogas tem sido o centro de debates em vários setores tanto governamentais como na sociedade em geral e se apresenta como um grave problema social e de saúde pública. ${ }^{1,2}$ Cerca de 246 milhões de pessoas, ou um pouco mais de 5\% da população mundial entre 15 e 64 anos de idade, usaram drogas ilícitas em 2013. Usuários de drogas problemáticos, por outro lado, somaram por volta de $27 \mathrm{mi}-$ lhões, dos quais quase metade são pessoas que fazem uso de drogas injetáveis. A dependência deve ser compreendida como uma condição crônica de saúde a qual, assim como diabetes ou hipertensão arterial, requer tratamento e cuidados sustentados a longo prazo. ${ }^{3}$

O Levantamento Nacional de Álcool e Drogas (I LENAD) realizado em 2006 em 143 cidades brasileiras mostrou que metade dos brasileiros não eram consumidores de álcool, porém os índices de uso nocivo e dependência eram altos entre os bebedores. Em 2012 (II LENAD), chamou a atenção dos pesquisadores o aumento da população que experimentou álcool mais cedo (13\% em 2006 para 22\% em 2012), sendo essa experimentação semelhante entre homens e mulheres. ${ }^{4}$

Dados recentes apontam o Brasil como uma das nações emergentes onde o consumo de cocaína — seja na forma intranasal (pó) ou fumada (crack, merla ou oxi) - está aumentando, enquanto na maioria dos países o consumo está diminuindo ${ }^{3}$; assim como classificam a maconha como a substância ilícita com maior prevalência de uso na população brasileira.

Embora a sociedade brasileira esteja ciente do problema das drogas, seu conhecimento acerca dos padrões de consumo e da dependência, bem como dos problemas associados ao uso, ainda são incipientes. O assunto ainda é tratado sob a ótica da repressão, da intolerância e do preconceito, mesmo quando são discutidos projetos de prevenção ou ainda nas questões médicas e de saúde. ${ }^{5}$

O Ministério da Saúde reconhece a exclusão social e a ausência de cuidados que atingem, de forma histórica e contínua, aqueles que sofrem pelo consumo de álcool e outras drogas e aponta para a necessidade da reversão dos modelos assistenciais contemplando as reais necessidades dessa população. ${ }^{6}$

A legislação vigente (Lei $n^{\circ} 11.343 / 2006$, que instituiu o Sistema Nacional de Políticas Públicas sobre Drogas, e Lei ${ }^{\circ} 11.705 / 2008$, que criou a Política Nacional sobre o Álcool) coloca o Brasil em posição de destaque internacional, definindo estratégias que visam o fortalecimento da rede de assistência aos usuários de álcool e outras drogas, enfatizando aspectos relativos à prevenção, atenção, reabilitação e integração social do usuário e do dependente de drogas, bem como ao endurecimento das penas pelo tráfico dessas substâncias. ${ }^{7}$

Quanto aos profissionais que atendem essa população, o que se tem observado são pessoas despreparadas para a abordagem do usuário, reforçando o preconceito e muitas vezes culpabilizando-o. ${ }^{2,8}$ A causa está ligada também à formação desses profissionais. Poucos são os cursos de graduação da área da saúde que incluem na sua grade curricular conhecimentos que preparem seus alunos para uma abordagem individualizada e humanizada em relação à dependência química.

O Ministério da Saúde tem buscado o fortalecimento da rede de assistência aos usuários de drogas principalmente voltada para a reabilitação e reintegração social na sociedade. ${ }^{8}$ Um braço importante dessa rede é a Estratégia Saúde da Família (ESF), que desenvolve ações de promoção, proteção e recuperação da saúde e prevenção de doenças e pode oferecer um cuidado integral à saúde dessas pessoas. ${ }^{9}$

Dentre os profissionais que integram a equipe da ESF, os agentes comunitários de saúde (ACS) são aqueles que convivem mais de perto com o problema das drogas. Eles são o elo entre a comunidade e os serviços de saúde e são multiplicadores de informações preventivas sobre o uso e abuso de drogas. ${ }^{10}$ Esses profissionais estão na condição de moradores do bairro onde atuam, o que favorece a convivência dinâmica com a realidade à sua volta, contribuindo na implantação e consolidação do novo modelo assistencial. ${ }^{11}$

Dessa forma, é importante que os ACS estejam preparados tanto na identificação dos usuários, como também para a abordagem e orientações adequadas.

Nesse contexto, este trabalho teve como objetivos conhecer o perfil dos ACS das Unidades de Saúde da Família (USF) do município de Sorocaba, São Paulo, e identificar a percepção e as formas de intervenção dos ACS acerca do uso e abuso de álcool e outras drogas nas áreas de abrangência da USF.

\section{MATERIAIS E MÉTODOS}

O referencial teórico adotado para este estudo foi a teoria das representações sociais ${ }^{12}$, que se apresenta como uma forma de interpretar e pensar a realidade cotidiana. Para Lefèvre e Lefèvre ${ }^{13}$, um modo legítimo (não o único) de conceber as representações sociais consiste em entendê-las como a expressão do que pensa ou acha determinada população sobre determinado tema. ${ }^{13,14}$

Trata-se de um estudo exploratório, descritivo, transversal, predominantemente qualitativo. Foram incluídos neste estudo os ACS que estavam inseridos nas USF do município de Sorocaba, São Paulo, no período da coleta de dados e que concordaram em participar voluntariamente por meio da assinatura do Termo de Consentimento Livre e Esclarecido. Os dados foram coletados diretamente com o sujeito participante por meio de entrevista no período de agosto a outubro de 2013. As entrevistas foram gravadas com autorização dos participantes e transcritas para análise posterior, apenas após a pesquisa ter sido aprovada pelo Comitê de Ética da Faculdade de Ciências Médicas e da Saúde da Pontifícia Universidade Católica de São Paulo (PUC-SP).

Foram utilizados como instrumentos de coleta de dados um questionário sociodemográfico e, para os dados qualitativos, outro instrumento com as seguintes questões: Das atividades desenvolvidas nos centros de atenção psicossocial (CAPS), quais delas você se identifica mais? Os novos dispositivos de saúde mental, especialmente os CAPS, exi- 
gem um trabalho em equipe multidisciplinar. Em sua opinião, como o enfermeiro se integra nessa equipe? Como foi o seu preparo para atuar no CAPS? Quais as facilidades e dificuldades para executar seu trabalho no CAPS?

\section{RESULTADOS E DISCUSSÃO}

Do total de 67 ACS inscritos nas USF do município, foram entrevistados 64. Não participaram do estudo três ACS que estavam afastados do trabalho por licença saúde e licença maternidade. A Tabela 1 mostra o perfil dos ACS que participaram da pesquisa.

No grupo pesquisado houve predominância de mulheres, o que significa que sobressaiu a visão feminina sobre o tema. A feminização aparece no setor de saúde como uma característica marcante e a categoria profissional de ACS também segue esse padrão. Desde o início da profissão, no ano de 1987, no Ceará, esse tem sido um trabalho exercido majoritariamente por mulheres. ${ }^{15,16}$

Esses profissionais estão nesse trabalho em média há aproximadamente cinco anos (com variação entre três e sete anos), condição para um bom conhecimento do território.

Os resultados qualitativos obtidos se seguem com as respectivas ideias centrais.

\section{As drogas como um dos maiores problemas nos bairros}

Na percepção dos ACS, o consumo de álcool e outras drogas é um comportamento em expansão que afeta diretamente os jovens e a família e, indiretamente, toda comunidade.
IC 1 - O primeiro sinal é o conflito nas famílias

Os ACS percebem mais de perto o problema das drogas, assim como podem interferir nessa realidade, uma vez que estabelecem um vínculo muito próximo com as famílias. Essa proximidade faz com que esses profissionais conheçam a dinâmica familiar e percebam os primeiros sinais do uso/ abuso das drogas que se traduzem pelo conflito e desorganização familiar. ${ }^{2,17}$

Sempre que acontece alguma coisa fora do normal eles já me comunicam: "aconteceu briga lá naquela família, vai dar uma olhada”, daí então através da própria comunidade ou da família eu acabo percebendo e indo atrás. Eu faço a visita e percebo que a mãe não tá legal, sempre preocupada, depressiva. Como moradora do bairro eu observo muita coisa. Tem famílias que têm muita confiança então já falam mesmo, as próprias mães reclamam que os filhos estão usando drogas, acabam falando para desabafar e buscar ajuda. Muitos fatores podem levar ao uso de drogas: decepções, revolta, depressão, problema financeiro, são famílias que já não têm boa estrutura. Também tem o histórico familiar, o pai, ou a mãe usa. (DSC)

Reforçando esse discurso, em um estudo sobre a percepção de adolescentes do sexo masculino usuários e ex-usuários de crack da cidade de Montes Claros em Minas Gerais, foi relatado o envolvimento de parentes no uso de drogas, principalmente o álcool e/ou o cigarro, sendo o pai aquele que mais as consumia. ${ }^{18}$ Estudos revelam também que as práticas familiares muitas vezes são estímulos para a experimentação e continuidade do uso de drogas. ${ }^{19}$

Tabela 1. Perfil dos agentes comunitários de saúde das Unidades de Saúde da Família do município de Sorocaba, São Paulo, 2014.

\begin{tabular}{|c|c|c|c|c|c|c|c|c|}
\hline Variáveis & USF 1 & USF 2 & USF 3 & USF 4 & USF 5 & Total & \multirow{2}{*}{$\%$} & \multirow{2}{*}{$\begin{array}{c}\text { Média } \\
\text { geral }\end{array}$} \\
\hline n & 10 & 10 & 14 & 19 & 11 & 64 & & \\
\hline \multicolumn{9}{|l|}{ Sexo } \\
\hline Feminino & 10 & 10 & 14 & 18 & 11 & 63 & 98,4 & \\
\hline Masculino & 0 & 0 & 0 & 1 & 0 & 1 & 1,6 & \\
\hline Idade* & 34,5 & 35,9 & 38 & 36,1 & 39,9 & & & 36,8 \\
\hline \multicolumn{9}{|l|}{ Estado civil } \\
\hline Casada(o) & 10 & 10 & 11 & 16 & 11 & 58 & 90,6 & \\
\hline Solteira(o) & 0 & 0 & 3 & 3 & 0 & 6 & 9,4 & \\
\hline \multicolumn{9}{|l|}{ Religião } \\
\hline Católica & 4 & 6 & 7 & 11 & 5 & 33 & 51,5 & \\
\hline Evangélica & 4 & 3 & 7 & 7 & 5 & 26 & 40,6 & \\
\hline Outras & 2 & 1 & 0 & 1 & 1 & 5 & 7,9 & \\
\hline Escolaridade** & 11,4 & 10,7 & 11,3 & 11,5 & 11,2 & & & 11,2 \\
\hline Tempo que trabalha na USF* & 7 & 3 & 3 & 4,4 & 7 & & & 4,8 \\
\hline Visitas por semana & 51 & 49 & 43 & 54 & 39 & & & 47,2 \\
\hline
\end{tabular}

USF: Unidade de Saúde da Família; *média em anos; **média dos anos de estudo. 


\section{IC2 - A relação tráfico de drogas e violência}

[...] é uma situação muito crítica que a gente vive aqui no bairro, a droga está por trás do aumento das brigas e dos assassinatos, começa com o comportamento agressivo na família e com a gente (ACS) também. Eu vejo as crises de abstinência, a violência e o roubo, eles não têm dinheiro para o vício e começam a quebrar tudo na casa. (DSC)

A percepção dos ACS sobre a questão do uso de drogas se confirma nas estatísticas mais recentes. Nos resultados do II LENAD, de 2012, observou-se que dois terços dos homens jovens bebedores problemáticos já se envolveram em uma briga com agressão no último ano. Esse índice sobe para $57 \%$ entre os que também usam cocaína. Sobre a violência doméstica, $6 \%$ dos brasileiros referiram ter sido vítima e em metade desses casos o parceiro que exerceu a violência havia bebido. ${ }^{5,19}$

\section{IC 3 - O tráfico de drogas é muito visível e tem} seu código

Aprender a reconhecer os códigos dos traficantes e dos usuários é uma necessidade do cotidiano dos ACS.

Aqui o tráfico de drogas é muito visível, nada é escondido, eles não disfarçam, às vezes usam na nossa frente. É como uma doença que está se espalhando pelo bairro, cada beco é uma boca de fumo...na minha micro área os meninos de $10 \mathrm{a}$ 12 anos usam e vendem durante o dia, e tem disputa de território de quem vende mais. Cada ponto é uma biqueira, na verdade a gente fala biqueira porque é o nome que eles dão, mas é um ponto de venda. Aí tem dia que eles gritam: " aqui é cinco, aqui é dez", e a gente sabe que é o preço do entorpecente, e assim eles fumam maconha o dia todo. Cada 10 casas que eu visito 5 tem problemas com o tráfico, em cada esquina tem um grupinho usando e vendendo drogas. A realidade está exposta nas ruas, então quando eu vou na casa nem fico questionando muito. (DSC)

\section{A identificação do usuário de drogas}

\section{IC1 - Usuários de crack e maconha}

Na percepção dos ACS, são as características dos usuários de crack que contribuem para o estigma que essas pessoas carregam e que muitas vezes os excluem do direito ao cuidado à saúde. ${ }^{20}$

Os usuários de crack ficam com o nariz e com os dedos queimados, tem uma respiração diferente, olhos vermelhos e não conseguem olhar diretamente nos olhos das pessoas. As unhas ficam pretas, as roupas sujas e com odor. Parece que estão sempre gripados. A fisionomia da pessoa, o jeito de falar, de se comportar, e pelo cheiro característico do usuário de maconha. Aqui já sei quem usa e quem não usa, quem é "nóinha" e quem não é. Os dentes ficam escuros e sujos e a aparência desleixada. O usuário de crack emagrece muito e tem uma aparência feia e triste. (DCS)
IC2 - Mudança de comportamento: do uso à dependência

$\mathrm{Na}$ descrição do comportamento foi possível perceber a evolução do uso, abuso até a dependência, ou seja, quando a droga passa a ocupar o centro da vida dessas pessoas, afastando-as do trabalho e do convívio familiar.

Eu percebo o comportamento diferente, eles passam a maior parte do dia na rua, nas esquinas, em grupinhos e têm um jeito desconfiado. Os usuários de cocaína são agitados e agressivos. Quando começam a usar drogas eles se recolhem, têm vergonha, e se afastam da gente porque a maioria a gente conhece a família. Com o tempo de uso param de trabalhar e maltratam família. Não tem diferença, são meninos e meninas, eles dormem durante o dia, não estudam, não trabalham. (DSC)

\section{IC 3 - Os usuários de álcool}

Assim como mostram as estatísticas, o uso e abuso de álcool se mostrou bastante prevalente tanto entre adultos como entre os jovens dos bairros pesquisados. ${ }^{6}$ Drogas lícitas como o álcool e o tabaco são as primeiras experimentadas pelos jovens, em geral muito precocemente e sem limite de doses.

$\mathrm{O}$ status de legalidade torna-os socialmente aceitos e largamente consumidos. Ocorre que, geralmente, o usuário que se torna dependente do álcool passa a buscar efeitos mais intensos nas drogas ilícitas. ${ }^{5}$

O uso do álcool é mais visível pelo número de bares no bairro, muitos adolescentes ficam no bar bebendo cerveja. O dependente de álcool é mais fácil reconhecer porque anda caindo e com o "corotinho", é difícil encontrar ele sóbrio. Também porque a família comenta as complicações na casa por causa da bebida. Alguns tremem bastante. Outros trabalham, tem uma vida normal, mas bebem a noite. Quando o marido é hipertenso, ou se está usando medicação são as esposas que falam se ele está fazendo uso de álcool. (DCS)

\section{As intervenções}

\section{IC 1 - O medo}

Há muita mistificação sobre a questão das drogas, exercendo ao mesmo tempo fascínio e provocando medo. ${ }^{21}$ Neste estudo, o medo está por trás de todas as falas dos ACS, o que muitas vezes os impede de intervir: "A intervenção é difícil, pois sabemos que a criminalidade é organizada". Embora os discursos possam traduzir respeito pelo usuário: “... eu procuro ajudar quando eles pedem ajuda, se a pessoa não quer não se faz nada, a gente nem tenta", por outro lado demonstram a falta de preparo na abordagem.

[...] não tive preparação, aprendi com o dia a dia, com a cara e a coragem. A gente pensa que está preparada, mas chega lá e vê uma situação nova e tem que agir naquele momento, preparada a gente nunca está. Nesse assunto a gente não tem pre- 
paro como para outras doenças, é muito complicado, a gente vai na casa e a mãe já fez de tudo e não resolveu [...] (DSC)

\section{IC 2 - A escuta}

[...] primeiro procuro abordar a família, porque na minha opinião quando a família aceita esse problema na casa, fica mais fácil da gente ajudar, pra gente ir direto com o usuário fica mais difícil, então primeiro, eu principalmente, começo na família e procuro conversar. (DSC)

\section{O preparo/capacitação para realizar intervenções}

\section{IC 1 - Falta de apoio psicológico e suporte}

Embora as USF promovam reuniões das equipes onde os casos mais complicados são objeto de discussão no Núcleo de Apoio à Saúde da Família e, se preciso, encaminhados aos grupos de apoio, ainda assim os ACS sentem falta de um suporte emocional e profissional frente às situações vivenciadas no dia a dia.

[...] o que falta mesmo é um suporte, porque nós moramos no bairro e é difícil ficar dando a cara a tapa para lidar com essas situações. O trabalho com os usuários abala o psicológico da gente, falta um apoio, pois fica cada vez pior a situação. Às vezes fico frustrada, me sinto impotente e vulnerável ao mesmo tempo. (DSC)

\section{IC2 - O apoio da equipe e dos enfermeiros}

Dentro da ESF o enfermeiro aparece como facilitador e orientador das intervenções e ações educativas realizadas pelos ACS, reafirmando o seu papel de cuidador preocupado com a promoção da saúde.

$\mathrm{O}$ enfermeiro tem se mostrado um elemento chave no processo da transformação social, participando no desenho e implementação de programas e projetos de promoção à saúde, prevenção do uso e abuso de drogas e integração social. ${ }^{22}$

Tento sempre conversar com o usuário e tenho muito apoio do enfermeiro para tomar as decisões. Inicialmente os familiares e usuários são convidados a comparecer à USF para conversar com enfermeiro, ou até pedimos para que ele realize uma visita na casa para aumentar o vínculo com o usuário. (DSC)

\section{A redução de danos}

A percepção da maioria dos ACS vem ao encontro do movimento proposto pela redução de danos (RD), ou seja, o sucesso de uma intervenção não segue "a lei do tudo ou nada", sendo aceitos objetivos parciais. Os ACS mais novos no cargo se mostraram mais comprometidos na busca de novas estratégias no enfrentamento do problema e foram mais favoráveis à RD. ${ }^{23}$

Se eles demonstram abertura para conversar, toco no assunto. Falo e trabalho pensando na redução de danos. São orientações sobre sexualidade, a gente tenta mostrar um caminho menos prejudicial. Os usuários estão usando mesmo, porém diminuir a quantidade ou substituir ameniza os danos, para eles e para família que também recebe orientações sobre a RD. É uma alternativa para tentar proporcionar ao usuário uma qualidade de vida melhor onde se não conseguimos afastá-los totalmente pelo menos reduzimos a frequência e a quantidade. (DSC)

Os discursos dos ACS sobre o consumo de drogas ficaram distantes do discurso tradicional, ligado a posturas repressivas, que focalizam principalmente as drogas ilegais e criminalizam o usuário.

Ao contrário, foi possível perceber nas falas dos ACS que as ações não devem ser impostas de "cima para baixo", por leis ou decretos, mas desenvolvidas com a participação ativa do usuário; e que a postura do profissional deve ser, antes de tudo, compreensiva e inclusiva.

\section{CONCLUSÕES}

As representações sociais dos ACS direcionam suas práticas. O consumo de drogas é considerado um problema de saúde no contexto assistencial em que atuam, mas falta-lhes capacitação e informação para uma abordagem adequada. Além disso, as situações vivenciadas no cotidiano de suas relações sociais e profissionais os levam a representar o problema como um fenômeno ligado à violência e ao medo, o que dificulta intervenções efetivas. Ações educativas para capacitar os ACS se constituem no caminho para o melhor enfrentamento dessa situação conflitante.

\section{REFERÊNCIAS}

1. Melo MT, Spanhol FJ, Argenta MI, organizadores. O complexo universo da dependência química. Palmas: Unitins; 2012.

2. Oliveira JF, McCallum CA, Costa HOG. Representações sociais de agentes comunitários de saúde acerca do consumo de drogas. Rev Esc Enferm USP. 2010;44(3):611-8.

3. United Nations Office on Drugs and Crime. World Drug Report 2015. New York: UNODC; 2015.

4. Laranjeira $\mathrm{R}$, organizador. II LENAD Levantamento Nacional de Álcool e Drogas: o consumo de álcool no Brasil: tendências entre 2006 e 2012 [Internet]. 2013 [acesso em 22 mar. 2015]. Disponível em: http:// inpad.org.br/wp-content/uploads/2013/04/LENAD_ PressRelease_Alcohol_RVW.pdf

5. Cazenave SOS, Chasin AAM. Análises toxicológicas e a questão ética. Rev Intertox Toxicol Risco Amb Soc. 2009;2(2):5-17.

6. Brasil. Ministério da Saúde. Secretaria de Atenção à Saúde. A Política do Ministério da Saúde para Atenção Integral a Usuários de Álcool e outras Drogas. Brasília: Ministério da Saúde; 2004.

7. Brasil. Secretaria Nacional de Políticas sobre Drogas. Legislação e Políticas Públicas sobre Drogas no Brasil. Brasília: SENAD; 2008. 
8. Gonçalves SSPM, Tavares CMM. Atuação do enfermeiro na atenção ao usuário de álcool e outras drogas nos serviços extra hospitalares. Esc Anna Nery Rev Enferm. 2007;11(4):586-92.

9. Brasil. Ministério da Saúde. Portal de saúde. Equipe de Saúde da Família. Brasília: Ministério da Saúde; 2004.

10. Araújo LF, Castanha AR, Barros APR, Castanha CR. Estudo das representações sociais da maconha entre agentes comunitários de saúde. Ciênc Saúde Coletiva. 2006;11(3):827-36.

11. Nunes MO, Trad LB, Almeida BA, Homem CR, Melo MCIC. O agente comunitário de saúde: construção da identidade desse personagem híbrido e polifônico. Cad Saúde Pública. 2002;18(6):1639-46.

12. Jodelet D. As representações sociais. Rio de Janeiro: Ed UERJ; 2000.

13. Lefèvre F, Lefèvre AMC. Depoimentos e discursos: uma proposta de análise em pesquisa social. Brasília: Liber Livro; 2005.

14. Sêga RA. O conceito de representação social nas obras de Denise Jodelet e Serge Moscovici. Anos 90. 2000;13:128-33.

15. Castanha AR, Araújo LF. Álcool e agentes comunitários de saúde: um estudo das representações sociais. PsicoUSF. 2006;11(1):85-94.

16. Fonseca RL, Alencar CA, Pereira CV, Fonseca MAMOL, Silveira AR. Percepção de usuários de crack sobre o tratamento em um Centro de Atenção Psicossocial Álcool e Outras Drogas. Rev APS. 2014;17(2):214-22.

17. Seleghim MR, Inoue KC, Santos JAT, Oliveira MLF. Aspectos da estrutura familiar de jovens usuários de crack: um estudo do genograma. Ciênc Cuid Saúde. 2011;10(4):795-802.

18. Capistrano FC, Ferreira ACZ, Silva TL, Kalinke LP, Maftum MA. Perfil sociodemográfico e clínico de dependentes químicos em tratamento: análises de prontuários. Esc Anna Nery. 2013;17(2):234-41.

19. Ronzani TM, Noto AR, Silveira OS. Reduzindo o estigma entre usuários de drogas: guia para profissionais e gestores. Juiz de Fora: UFJF; 2014.

20. Cavalcante MBPT, Alves MDS, Barroso MGT. Adolescência, álcool e drogas: uma revisão na perspectiva da promoção da saúde. Esc Anna Nery Rev Enferm. 2008;12(3):555-9.

21. Niel M, Silveira DX, organizadores. Drogas e redução de danos: uma cartilha para profissionais de saúde. São Paulo: PROAD UNIFESP; 2008.

22. Gelbcke FL, Padilha MICS. O fenômeno das drogas no contexto da promoção da saúde. Texto Contexto Enferm. 2004;13(2):272-9.

23. Passos EH, Souza TP. Redução de danos e saúde pública: construções alternativas à política global de "guerra às drogas". Psicol Soc. 2011;23(1):154-62. 